\title{
The Sleeve-Cap Part Drafting Method of the General-Purpose Sleeve Pattern and the Verification of Compatibility ${ }^{+}$
}

\author{
Cho Kyunghee \\ Invited Prof., Dept. of Textiles \& Fashion Design, Faculty of Design, Hansei University
}

\begin{abstract}
This study devised and drew custom sleeve patterns by using a regression equation with the data from 7 models along with the sleeve that was slightly modified to make the general-purpose sleeve pattern.

To devise a general-purpose sleeve pattern, the sleeve pattern was drawn as an object for comparison by applying the Bunka drafting system (sleeve pattern by the Bunka drafting system) to the basic upper garment. Actual sleeves, made by using the three types of patterns above, were created and tested by models. Next, 30 panel members participated in a sight test of the compatibility of the sleeves to examine the validity of the sleeve drafting method acquired using the regression equation.

The test proved that the custom sleeve pattern and the general-purpose sleeve pattern were more suitable for the characteristics of arm structures. Thus, the new sleeve-cap part drafting method using the regression equation was shown to have validity.

As a result, since a very significant correlation was obtained for the body measurement figures and the basic pattern of the adequate basic pattern of the sleeves, this study concludes that it is possible to come up with primary data that can be widely used by increasing the number of subjects.
\end{abstract}

Key Words : general-purpose sleeve pattern, sleeve-cap part, regression equation, sensory test, verification of compatibility

\section{Introduction}

In the mass-produced ready-made clothes industry, the product pattern is being prepared with the plane drawing such as CAD in almost every case. In that sense, the highly compatible pattern design based on the human character istics data is important. It is generally known that

\footnotetext{
+ This Paper is an excerpt from the doctoral dissertation.

Corresponding author ; Cho Kyunghee, Tel.+82-10-3210-4033, Fax.+82-31-450-5222,

E-mail : kyonghee-cho@hanmail.net
} 
Cho Kyunghee / The Sleeve-Cap Part Drafting Method of the General-Purpose Sleeve Pattern and the Verification of Compatibility

the compatibility around the shoulder and upper arm greatly relates to the design of the armhole with the good wear sensation and beautiful form. Good compatibility is concerned with the good or bad pattern. Hence, in order to enhance the human costume compatibility with a wearer, it is important to check the size and pattern factors of a human body.

In the precedent study ${ }^{11)}$, the conditions ${ }^{2 / 3)}$ of the compatibility with the human body to make the sleeve for the basic pattern were clarified in the relation between the pattern and the human body, the three-dimensional form, and the relation of the sleeve pattern data with the human body's form data was considered by measuring the required length from the compatible pattern collected from the draping. The basic bodice pattern and the basic sleeve pattern found in the precedent study ${ }^{11)}$ are hereinafter called the compatible basic bodice pattern and the compatible basic sleeve pattern respectively. It resulted in the regression equation that is the basic of the drafting system focusing on the sleeve-cap height, sleeve width, and sleeve-cap width that are the components of the sleeve pattern but attained the drafting system as the sleeve for the basic pattern.

In the precedent study ${ }^{24)}$, the explanatory variable was reviewed and reported with the measurement value of a basic human body, the measurement value of the form of a human body, and the measurement value of the compatible basic bodice pattern to derive the pattern-making method and the calculation formula of the high sleeve-cap part generally utilized as the basic sleeve pattern for education. The equation to calculate the dimensions of each sleeve-cap part showed the real difference from the conventional sleeve making method ${ }^{5) \sim 21)}$.
Hence, it can be used for various clothes like the general-purpose basic sleeve pattern for an adult female. It is necessary to devise the compatible and general-purpose sleeve pattern making method for an adult female on the basis of the theoretical study on the relation between a human body and the pattern.

In the study, the basic sleeve pattern made with the estimated value of the regression equation and the basic sleeve type slightly modified to prepare it as the general-purpose basic sleeve pattern were devised and produced. Furthermore, in order to derive the general-purpose basic sleeve pattern, the basic sleeve pattern prepared with the Bunka drafting system $^{14)}$ by using the compatible basic bodice pattern $^{1)}$ as the comparison subject was made. The effectiveness of the theory of making the pattern of the sleeve-cap part through the compatibility verification experiment is to be reported by producing the actual object based on the three kinds of the sleeve patterns.

\section{Methodology}

\section{Samples}

The three kinds of sleeves are used as samples.

1) The Basic Sleeve Pattern for Individuals

It is the basic sleeve pattern prepared with the regression equation in the precedent study ${ }^{24)}$. The item with the significantly high contribution rate in the regression analysis result was selected. It is the sleeve prepared with the estimated value of the regression equation of each basic sleeve part by focusing on the sleeve pattern components being composed of the sleeve-cap height, sleeve width, sleeve-cap 
width $^{1)}$, sleeve-cap curve and being derived from the explanatory variables such as the measurement value of the human form and the measurement value of the bodice pattern. Hereinafter, it is referred to as the individual sleeve.

\section{2) Main Sleeve Pattern}

It is the basic sleeve pattern modified to make the basic sleeve pattern for individuals as the general-purpose basic type. The basic sleeve pattern is called the main sleeve pattern.

The basic bodice pattern was prepared by modifying the compatible basic bodice pattern made in the precedent study ${ }^{11)}$. The compatible basic bodice pattern was a bit shorter than $\mathrm{B} / 2+6 \mathrm{~cm}$, the bodice breadth of the Bunka basic bodice pattern and was $B / 2+5.34 \mathrm{~cm}$ in average. The shortage of $0.66 \mathrm{~cm}$ caused from it was calculated ${ }^{22)}$ proportionately and added to the back breadth, side breadth ${ }^{23)}$, and chest breadth. Actually, the individual data were modified with the allowance of the basic pattern of each individual object. It is called the main bodice pattern.

\section{3) The Sleeve Pattern of the Bunka Drafting System}

It is the basic sleeve pattern prepared with the Bunka drafting system ${ }^{14)}$ by using the compatible basic bodice pattern for the comparison of the drafting system. It is hereinafter referred to as the sleeve pattern of the Bunka drafting system.

The seven wearing experiment models of the study in total are the subjects of the precedent study $^{11)}$ such as six FRP recovered shapes ${ }^{24)}$ and one standard figure and are classified into the three types such as 3 obese body type samples, 2 average body type samples, and 2 thin body type samples. The cloth used to make experiment clothes is the color sheeting with the starch taken off.

\section{The Drafting System of the Basic Sleeve Pattern for Individuals}

The basic sleeve pattern for individuals was prepared with the estimated value of the regression equation of each part of the basic sleeve pattern on the basis of the results of the precedent study ${ }^{24)}$. The preparation results of the basic sleeve pattern for individuals is presented in <Figure 2>.

\section{The Drafting System of the Main Sleeve Pattern}

It is made in the order of ${ }^{2)}$ stated above to make the general-purpose sleeve. The preparation results of the main sleeve pattern is presented in <Figure 2$\rangle$.

If the $0.66 \mathrm{~cm}$ shortage of the compatible basic bodice pattern stated above is calculated $^{22)}$ proportionately, the back breadth was $0.15 \mathrm{~cm}$ with the side breadth of $0.39 \mathrm{~cm}$ and the chest breadth of $0.12 \mathrm{~cm}$. Hence, it can be used as the general-purpose basic sleeve pattern by adding the portion armpit added to the back breadth, side breadth, and chest breadth to the integer term of the regression equation of the sleeve width and the sleeve-cap width. The allowance of the back breadth, side breadth, and chest breadth was divided with the shoulder breadth left as it is to make the bodice width wide so that it was opened ${ }^{25)}$ with the allowance in the position of the back armpit point, the side line, and the front armpit point and the portion was added to the sleeve pattern in accordance with it.

The quantity of the side breadth of the bodice 
Cho Kyunghee / The Sleeve-Cap Part Drafting Method of the General-Purpose Sleeve Pattern and the Verification of Compatibility

breadth changed by inserting the allowance into $\mathrm{AH}$ to open it as the main bodice pattern was determined with draping. In the draping, the compatibility state of each model was checked with the compatibility conditions ${ }^{2 / 3)}$ of the basic pattern as advocated by Miyoshi with the side breadth determined and with the same quantity added to the sleeve width. Actually, the individual data were modified with he allowance of the basic pattern of each individual subject.

\section{The Drafting System of the Sleeve Pattern of the Bunka Drafting System}

The basic sleeve type is prepared with the Bunka drafting system ${ }^{14)}$ to compare with the individual sleeve. The preparation results of the Bunka sleeve pattern are presented in <Figure 2).

The Japanese Bunka pattern with the scientific theory systematically organized through the experiments and practices was modified in 1999. The new basic Bunka pattern is the basic pattern mostly frequently used among the basic patterns used in the Japanese educational institutions.

\section{How to Do the Sensory Test with Models}

The three kinds of basic sleeve patterns were prepared for each model with the wearing evaluation performed with the sensory test to check the compatibility and validity.

As for the evaluation method, the sensory test was done with the wearing photos of the three kinds of basic sleeve patterns in seven models. The panel consists of the total 30 persons including 11 faculty members taking care of clothes pattern modeling practices(Japan, Bunka Women's University) and having the technical evaluation capability, 7 graduate students majoring in clothes pattern modeling, and 12 pattern designers of apparel companies(HIROKO KOSHINO INTERNATIONAL CORPORATION BIS Dept. Modelist). The 5-stage evaluation with the "good" to "bad" compatibility for the 11 items presented as follows was performed to assign the points from 5 to 1 in the order of good evaluation. The items of the sensory test were set up in accordance with the basic sleeve pattern compatibility check items ${ }^{26)}$ of the precedent study ${ }^{11)}$. The decision items are presented as follows.

As for the inspection method, the wearing evaluation based on photos was performed. The compatibility of the total sleeve was reviewed by performing the analysis of one-way and multi-way layout variances for the evaluation items.

In order to verify the significance of the main pattern and the comparative pattern, the JUSE-QCAS statistical program was used.

(The decision items of the sensory test)

(1) Are arms covered naturally?

(2) Does the lengthwise strand cross the sleeve-cap line?

(3) Is the orthogonal state of the lengthwise strand of the sleeve-cap line and the crosswise strand of the sleeve width line discrepant? (Front, side, and back)

(4) Is it compatible with the arm form?

(5) Does the sleeve attachment angle ${ }^{27)}$ follow the outer line slope ${ }^{28)}$ of the arm of each individual subject?

(6) Is the distribution of the ease portion of the sleeve-cap part appropriate?

(7) Is the height of the sleeve-cap suitable?

(8) Is the local diagonal crease or pulled crease shown in aggregate?

(9) Is the allowance of the sleeve width around 
the upper arm suitable?

(10) Is the allowance (including the covered portion $^{29)}$ ) of the sleeve-cap width suitable?

(11) Is the organization (based on the ease technology) of the surface of the non-zero Gaussian curvature in the edge of the shoulder suitable?

\section{Results and Discussion}

\section{The Preparation Results and Consideration of the 3 Kinds of Sleeve Patterns}

<Figure 1> shows the example of the preparation results of the main bodice pattern.
<Figure 2> shows the example of the preparation results of the sleeve-cap parts of the individual sleeve, main sleeve, and sleeve pattern of the Bunka drafting system. Furthermore, the bodice pattern of the individual sleeve and the sleeve pattern of the Bunka drafting system used the compatible bodice pattern $^{1)}$.

The individual sleeve was found with the regression equation so that the discrepancy of the side line of the bodice and the seam under the sleeve may occur when it is connected to the compatible basic bodice pattern. For that reason, the front and back sleeve width dimension is in accordance with the side seam line of the bodice to slightly adjust the seam

$<$ Table 1> Results of measurement items

\begin{tabular}{l|c|c|c|c|c|c|c|c|c}
\hline measurement items & Model A & Model B & Model C & Mbdel D & Model E & Model F & Model G & Mean & S.D. \\
\hline side breadth ease(front) & 0.53 & 0.10 & 0.15 & 0.55 & 0.90 & 1.83 & 0.46 & 0.65 & 0.59 \\
\hline side breadth ease(back) & 0.50 & 1.12 & 0.33 & 0.85 & 0.32 & 0.38 & 0.46 & 0.57 & 0.30 \\
\hline \hline
\end{tabular}

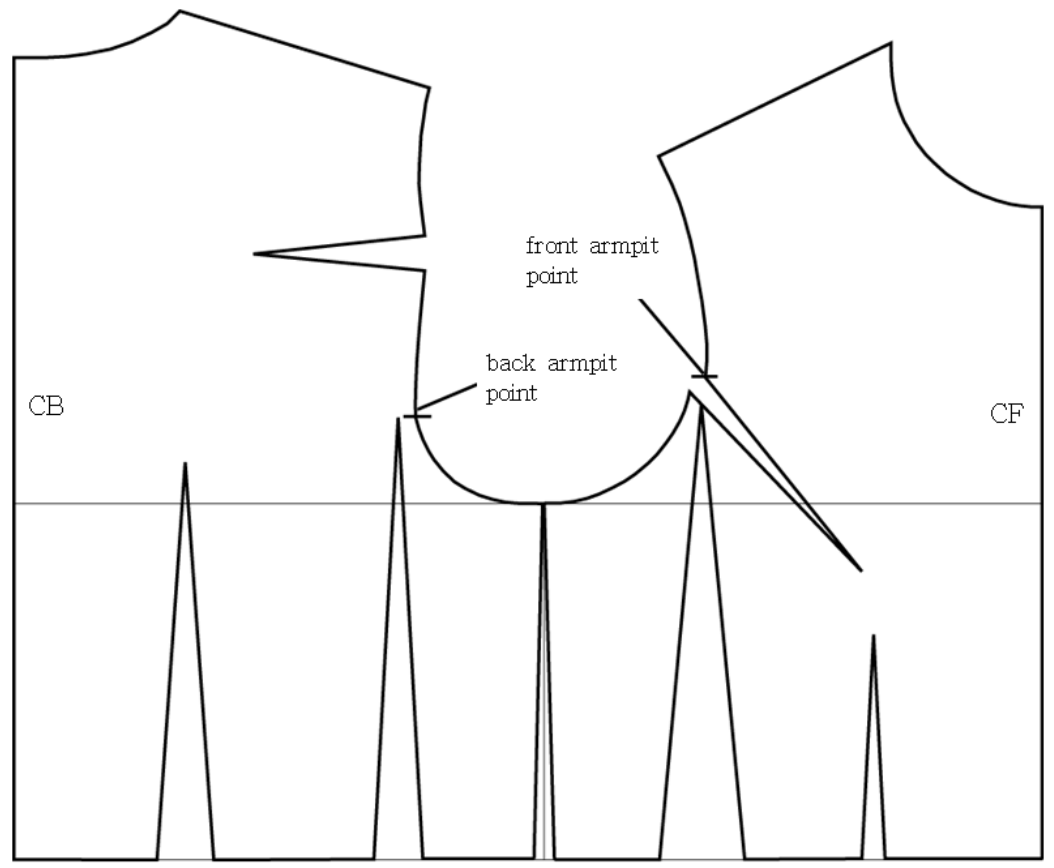

<Fig. 1> 1 example of the making pattern of Main bodice pattern(Model E) 
Cho Kyunghee / The Sleeve-Cap Part Drafting Method of the General-Purpose Sleeve Pattern

and the Verification of Compatibility

(ModelE)

\begin{tabular}{l|r} 
& unit $: \mathrm{cm}$ \\
\hline \hline \multicolumn{1}{c}{ measurement items } & measures \\
\hline bust circumference & 75.84 \\
waist circumference & 64.94 \\
upper arm girth & 24.76 \\
armscye circumference & 35.07 \\
SP b point scye depth & 13.78 \\
AH(bodice pattern) & 38.41 \\
\hline B-height of sleeve cap & 13.12 \\
B-sleeve width & 29.28 \\
B-sleeve cap width & 16.95 \\
\hline K-height of sleeve cap & 13.87 \\
K-sleeve width & 29.54 \\
K-sleeve cap width & 18.18 \\
\hline H-height of sleeve cap & 13.87 \\
H-sleeve width & 31.23 \\
H-sleeve cap width & 18.65 \\
\hline \hline
\end{tabular}

B : Sleeve Pattern of the Bunka drafting system (Bunka Sleeve)

K : Individual Sleeve Pattern(Individual Sleeve)

$\mathrm{H}$ : Main Sleeve Pattern(Main Sleeve)

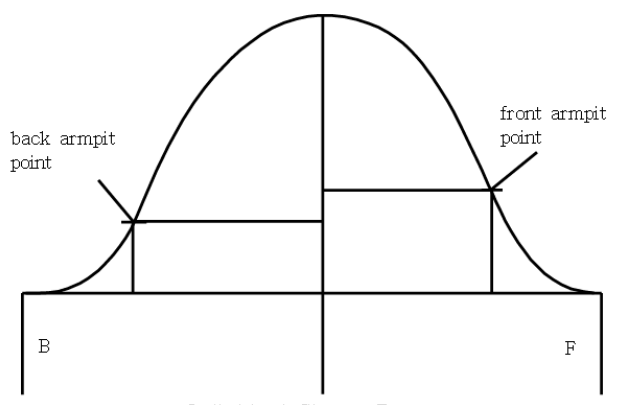

Individual Sleeve Pattern

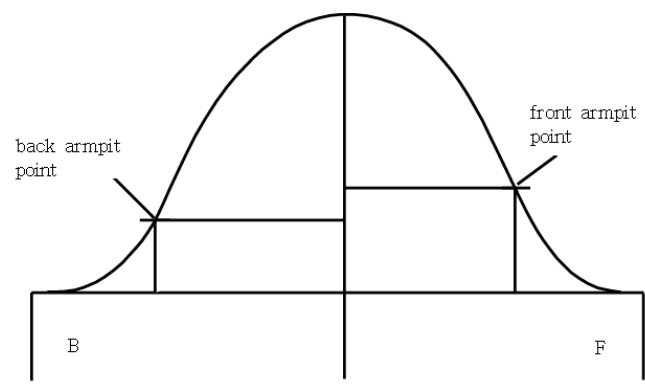

Main Sleeve Pattern

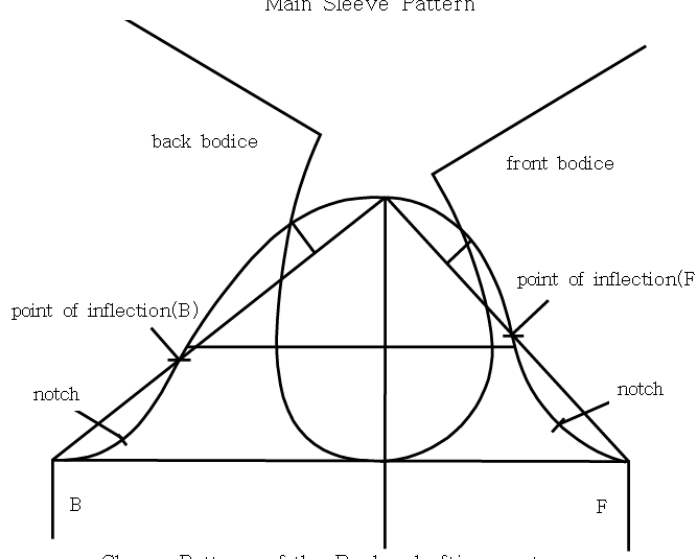

Sleeve Pattern of the Buntra drafting system

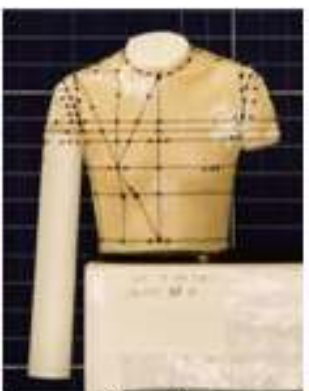

front

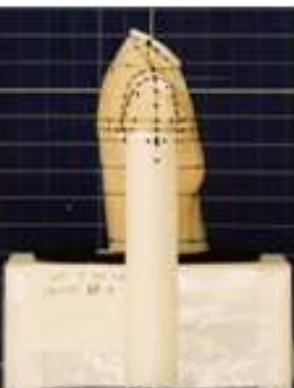

side

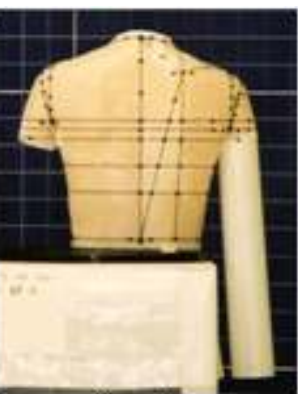

back

<Fig. 2> Results of sleeve pattern making(Model E) 
line under the sleeve. The curve in the sleeve-cap part was drawn by connecting the ones divided into equal parts. ${ }^{30)}$

$<$ Table $1>$ shows the allowance added to the front and back side breadth of the main bodice pattern.

The general-purpose characteristics can be obtained by adding the allowance of the front and back side breadth of the 7 samples to the front and back sleeve width of the individual sleeve pattern. Moreover, the main sleeve pattern can be prepared by marking the position of the front and back sleeve-cap width by providing the allowance of $0.12 \mathrm{~cm}$ and $0.15 \mathrm{~cm}$ respectively from the front and back armpit points of the individual sleeve pattern. At that moment, the sleeve-cap curve was drawn to cross the middle of the provided portion.

Furthermore, as shown in <Table 2>, the length of the diagonal lines ${ }^{29)}$ of the front and back sleeve-caps of the individual basic sleeve pattern was measured. As for the length of the diagonal lines of the front and back sleeve-caps of the individual basic sleeve pattern produced with the regression equation, the ease part is added to the front and back $\mathrm{AH}$ dimensions of the compatible bodice pattern, and it can be used as the sleeve pattern.

\section{The Results of Wearing by Models}

<Figure 3> shows the example of the wearing results of the 7 models of the basic sleeve pattern for individuals, main sleeve pattern, and sleeve pattern of the Bunka drafting system. As for the photo on the side, the sleeve-cap line was set to cross the surface around the armpit. $^{31)}$

The value in the figure shows the total average of the total evaluation items.

\section{The Review Results and Consideration of the Sensory Test}

\section{1) Evaluation Results}

As the results of performing the decision on the sensory test done by the panel of 30 persons through the observation of the wearing state of the experiment by using the front, side, and back photos of the models wearing the experiment costumes made as the sleeve pattern of the Bunka drafting system, basic sleeve pattern for individuals, and main sleeve pattern, the total evaluation point (average) of the total question items is presented. The total evaluation is presented in $\langle$ Table 3$\rangle$ as follows.

<Table 2> Results of measurement items

\begin{tabular}{c|c|c|c|c|c|c}
\hline \hline & (1) & (2) & (1)-(2) & (3) & $(4)$ & $(3)$-(4) \\
\hline Model A & 19.78 & 19.11 & 0.67 & 21.62 & 21.46 & 0.16 \\
\hline Model B & 20.07 & 18.89 & 1.18 & 21.62 & 20.22 & 1.40 \\
\hline Model C & 20.18 & 19.58 & 0.60 & 23.07 & 21.37 & 1.70 \\
\hline Model D & 20.88 & 19.56 & 1.32 & 23.88 & 22.44 & 1.44 \\
\hline Model E & 19.82 & 18.01 & 1.81 & 20.70 & 20.40 & 0.30 \\
\hline Model F & 21.80 & 21.62 & 0.18 & 25.23 & 24.28 & 0.95 \\
\hline Model G & 20.58 & 19.70 & 0.88 & 21.41 & 21.08 & 0.34 \\
\hline \hline
\end{tabular}

(1)-(2) : sleeve curve diagonal line(F)-bodice front $\mathrm{AH}$

(3)-(4) sleeve curve diagonal line(B)-bodice back $\mathrm{AH}$ 
Cho Kyunghee / The Sleeve-Cap Part Drafting Method of the General-Purpose Sleeve Pattern and the Verification of Compatibility

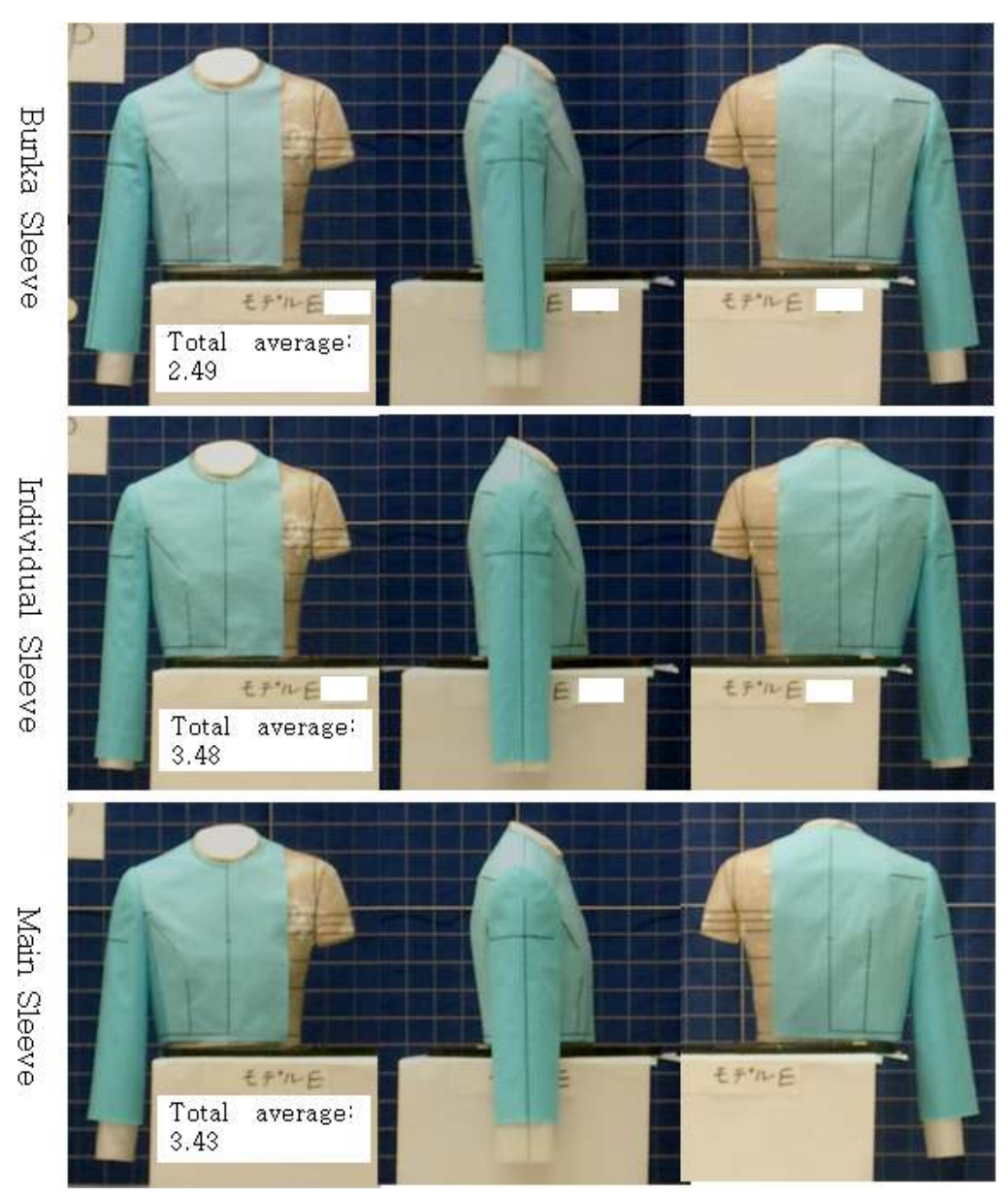

<Fig. 3> Wear test by the Model E

Generally, the individual sleeve and the main sleeve received the evaluation of three or more points in average. The evaluation of the individual sleeve and the main sleeve showed the result significantly higher than that of the sleeve of the Bunka drafting system of the 2 points in average over the total items in the verification of the significant difference. Namely, it was more compatible with the form characteristics of a human arm so that the sleeve drafting system was significant on the basis of the regression equation.
Hence, in the result of the compatibility verification experiment of the drafting system of the sleeve-cap part, the compatibility of the new sleeve drafting system and the effectiveness of the drafting theory were verified.

The evaluation item, "(4)Is it compatible with the arm form?", having the meaning of the total evaluation of the compatibility of the total sleeve, can be the item directly connected to the evaluation of the compatible state of the total arm and sleeve. The analysis results on (4) are stated below. Regarding the evaluation item, 
<Table 3> Results of sensory test

\begin{tabular}{|c|c|c|c|c|c|c|c|c|}
\hline 1 Bunka Sleeve & 2 Individual Sleeve & Mean1 & Mean2 & $(1-2)$ & Upper(95\%) & Lower(95\%) & $1 \mathrm{~s} \mathrm{~d}$ & t-test \\
\hline (1) & (1) & 2.281 & 3.381 & -1.100 & -0.901 & -1.299 & 0.199 & $* *$ \\
\hline (2) & $(2)$ & 2.391 & 3.843 & -1.452 & -1.253 & -1.652 & 0.199 & ** \\
\hline (3)-front & (3)-front & 2.719 & 3.424 & -0.705 & -0.505 & -0.904 & 0.199 & *** \\
\hline (3)-side & (3)-side & 2.567 & 3.552 & -0.986 & -0.786 & -1.185 & 0.199 & $* *$ \\
\hline (3)-back & (3)-back & 2.662 & 3.510 & -0.848 & -0.648 & -1.047 & 0.199 & $* *$ \\
\hline (4) & (4) & 2.343 & 3.252 & -0.910 & -0.710 & -1.109 & 0.199 & $* *$ \\
\hline (5) & (5) & 2.605 & 3.429 & -0.824 & -0.624 & \begin{tabular}{l|l|}
-1.023 \\
\end{tabular} & 0.199 & $* *$ \\
\hline (6) & (6) & 2.562 & 3.429 & -0.867 & \begin{tabular}{l|l|}
-0.667 \\
\end{tabular} & \begin{tabular}{l|l|}
-1.066 \\
\end{tabular} & 0.199 & $* *$ \\
\hline (7) & (7) & 2.638 & 3.443 & -0.805 & -0.605 & -1.004 & 0.199 & $* *$ \\
\hline 8 & 8 & 2.124 & 3.362 & -1.238 & -1.039 & -1.438 & 0.199 & $* *$ \\
\hline (9) & (9) & 2.481 & 3.400 & -0.919 & -0.720 & \begin{tabular}{|l|}
-1.118 \\
\end{tabular} & 0.199 & $* *$ \\
\hline (10) & (10) & 2.267 & 3.319 & -1.052 & -0.853 & \begin{tabular}{l|}
-1.252 \\
\end{tabular} & 0.199 & $* *$ \\
\hline (11) & (11) & 2.471 & 3.471 & -1.000 & -0.801 & \begin{tabular}{l|l}
-1.199 \\
\end{tabular} & 0.199 & $* *$ \\
\hline \multicolumn{9}{|c|}{ **:p<.01 、*: $\mathrm{p}<.05$} \\
\hline 1 1 Bunka Sleeve & 2 Main Sleeve & Mean1 & Mean2 & $\begin{array}{l}(1-2) \\
\end{array}$ & Upper(95\%) & Lower(95\%) & ls d & t-test \\
\hline (1) & (1) & 2.281 & 3.457 & -1.176 & -0.975 & -1.378 & 0.202 & $* *$ \\
\hline (2) & $(2)$ & 2.391 & 3.686 & -1.295 & -1.094 & -1.497 & 0.202 & $* *$ \\
\hline (3)-front & (3)-front & 2.719 & 3.438 & -0.719 & -0.518 & -0.921 & 0.202 & $* *$ \\
\hline (3)-side & (3)-side & 2.567 & 3.348 & -0.781 & -0.579 & -0.983 & 0.202 & $* *$ \\
\hline (3)-back & (3)-back & 2.662 & 3.448 & -0.786 & -0.584 & -0.987 & 0.202 & $* *$ \\
\hline (4) & $(4)$ & 2.343 & 3.238 & -0.895 & -0.694 & -1.097 & 0.202 & $* *$ \\
\hline (5) & (5) & 2.605 & 3.243 & -0.638 & -0.437 & -0.840 & 0.202 & $* *$ \\
\hline (6) & (6) & 2.562 & 3.319 & -0.757 & -0.556 & -0.959 & 0.202 & $* *$ \\
\hline (7) & $(7)$ & 2.638 & 3.405 & -0.767 & -0.565 & -0.968 & 0.202 & *** \\
\hline 8 & 8 & 2.124 & 3.300 & -1.176 & -0.975 & -1.378 & 0.202 & $* *$ \\
\hline (9) & (9) & 2.481 & 3.481 & -1.000 & -0.799 & -1.202 & 0.202 & $* *$ \\
\hline (10) & (10) & 2.267 & 3.414 & -1.148 & -0.946 & -1.349 & 0.202 & $* *$ \\
\hline (11) & (11) & 2.471 & 3.424 & -0.952 & -0.751 & -1.154 & 0.202 & $* *$ \\
\hline
\end{tabular}

“4) Is it compatible with the arm form?", the three factors such as the sleeve drafting type, body type, and panel were considered.

2) The Results and Consideration of the Analysis of Multi-Way Layout Variances on the Evaluation Item (4)

(1) The Relation of the Sleeve Drafting Type to the Subject

The results of the analysis of multi-way layout variances are shown in $\langle$ Table 4$\rangle$. The effectiveness on the effect among the individual levels of the three factors such as sleeve drafting type, body type, and panel was accepted. Furthermore, the relation of the sleeve drafting type with the subject showed the results of the existence of the interaction. There is no interaction between the factor $A$ and the factor $C$ so that the distribution ratio and the contribution rate became higher as the result of executing the automatic pooling. 
Cho Kyunghee / The Sleeve-Cap Part Drafting Method of the General-Purpose Sleeve Pattern and the Verification of Compatibility

\begin{tabular}{|c|c|c|c|c|c|c|c|c|}
\hline & factor & SS & $\mathrm{df}$ & $\mathrm{V}$ & $\mathrm{F}$ & $\mathrm{P}$ & contribution ratio & $\mathrm{E}(\mathrm{V})$ \\
\hline & A & 37.207 & 2 & 18.604 & $22.896 * *$ & 0.000 & 11.726 & \\
\hline & B & 5.030 & 2 & 2.515 & $3.095 *$ & 0.049 & 1.122 & \\
\hline & $\mathrm{AB}$ & 17.970 & 4 & 4.493 & $5.529 * *$ & 0.000 & 4.851 & \\
\hline & C & 76.996 & 29 & 2.655 & $3.268 * *$ & 0.000 & 17.609 & \\
\hline & $\mathrm{AC}$ & 33.904 & 58 & 0.585 & 0.719 & 0.918 & 0.000 & \\
\hline & $B C$ & 38.081 & 58 & 0.657 & 0.808 & 0.815 & 0.000 & \\
\hline \multirow[t]{2}{*}{$\mathrm{e}$} & $\mathrm{ABC}$ & 94.252 & 116 & 0.813 & & & 64.691 & 0.810 \\
\hline & 계 & 303.441 & 269 & & & & & \\
\hline
\end{tabular}

after pooling

\begin{tabular}{l|l|r|r|r|r|r|r|r}
\hline \hline & factor & \multicolumn{1}{c|}{ SS } & \multicolumn{1}{c|}{ df } & \multicolumn{1}{c|}{ V } & F & P & contribution ratio & E(V) \\
\hline & $\mathrm{A}$ & 37.207 & 2 & 18.604 & $25.963 * *$ & 0.000 & 11.790 & \\
\hline & $\mathrm{B}$ & 5.030 & 2 & 2.515 & $3.510 *$ & 0.032 & 1.185 & \\
\hline & $\mathrm{AB}$ & 17.970 & 4 & 4.493 & $6.270 * *$ & 0.000 & 4.978 & \\
\hline & $\mathrm{C}$ & 76.996 & 29 & 2.655 & $3.705 * *$ & 0.000 & 18.526 & \\
\hline $\mathrm{e}$ & $\mathrm{ABC}$ & 166.237 & 232 & 0.717 & & & 63.521 & 0.720 \\
\hline & 계 & 303.441 & 269 & & & & & \\
\hline \hline
\end{tabular}

**: $\mathrm{p}<.01 、 *: \mathrm{p}<.05$

A factor: drafting type of sleeve, B factor: body type, C factor: panel

$\langle$ Table $5>$ Results of sensory test

\begin{tabular}{l|c|c|c|c|c|c|c|c}
\hline \hline Drafting Type & Variables & No. of Data & Total & Minimum & Maximum & Mean & S.D. & C.V. \\
\hline Bunka Sleeve & $(4)$ & 210 & 492 & 1 & 5 & 2.343 & 0.996 & 0.425 \\
\hline Individual Sleeve & $(4)$ & 210 & 683 & 1 & 5 & 3.252 & 1.048 & 0.322 \\
\hline Main Sleeve & (4) & 210 & 680 & 1 & 5 & 3.238 & 0.974 & 0.301 \\
\hline \hline
\end{tabular}

(2) Relation of the Total Body Type with the Drafting Types of the Three Kinds of Sleeves

The drafting types of the three kinds of sleeves were considered on the basis of the total body type. As shown in $\langle$ Table 5>, the individual sleeve and the main sleeve generally received the evaluation of three or more points in average and received the evaluation being significantly better than that of the sleeve of the Bunka drafting method.

(3) Relation of the Three Body Types with the Drafting Types of Sleeves

As shown in $\langle$ Table 6$\rangle$, the 7 samples of the study were classified into the three body types based on BMI, and the relation of the sleeve 
with the drafting type was considered. As shown in $\langle$ Table 6$\rangle$, it is more or less compatible in the thin body type but tends to be incompatible in the obese body type so that the gap ratio is different for each sleeve drafting type. In the average body type, the individual sleeve was a bit higher. However, in the main sleeve, the average of the obese body type showed the high result. In the comprehensive sense, the main sleeve is advantageous to the obese body type. The sleeve drafting method based on the regression equation is effective. It was found that the drafting method for the Bunka sleeve should be improved to enhance the compatibility level in case of the obese body type.
(4) The Evaluation Results of the Total Sleeve Compatibility Level

The median was found for each drafting type of the sleeve to exclude the ones being 1.5 or more deviation from the analytical data. Regarding the average of the evaluation after pooling, the difference between the evaluation result of the total sleeve and that of the sleeve of the Bunka drafting method became more clearer in the relation of the drafting method of the three types as shown in $\langle$ Table 7$\rangle$.

$<$ Table 6> Results of sensory test

Sleeve Pattern of the Bunka drafting system

\begin{tabular}{l|c|c|c|c|c|c|c|c}
\multicolumn{1}{c|}{ Bodytype } & Variables & No. of Data & Total & Minimum & Maximum & Mean & S.D. & C. V. \\
\hline thin & 4 & 60 & 151 & 1 & 5 & 2.517 & 0.892 & 0.355 \\
\hline standard & 4 & 90 & 209 & 1 & 5 & 2.322 & 1.120 & 0.482 \\
\hline obese & 4 & 60 & 132 & 1 & 5 & 2.200 & 0.879 & 0.400 \\
\hline \hline
\end{tabular}

Individual Sleeve Pattern

\begin{tabular}{l|c|c|c|c|c|c|c|c}
\hline \multicolumn{1}{c|}{ Bodytype } & Variables & No. of Data & Total & Minimum & Maximum & Mean & S.D. & C.V. \\
\hline thin & 4 & 60 & 208 & 1 & 5 & 3.467 & 1.049 & 0.303 \\
\hline standard & 4 & 90 & 301 & 1 & 5 & 3.344 & 1.072 & 0.321 \\
\hline obese & 4 & 60 & 174 & 1 & 5 & 2.900 & 0.933 & 0.322 \\
\hline \hline
\end{tabular}

Main Sleeve Pattern

\begin{tabular}{l|c|c|c|c|c|c|c|c}
\hline \hline \multicolumn{1}{c|}{ Bodytype } & Variables & No. of Data & Total & Minimum & Maximum & Mean & S.D. & C. V. \\
\hline thin & 4 & 60 & 205 & 2 & 5 & 3.417 & 0.926 & 0.271 \\
\hline standard & 4 & 90 & 292 & 1 & 5 & 3.244 & 0.998 & 0.308 \\
\hline obese & 4 & 60 & 183 & 1 & 5 & 3.050 & 0.964 & 0.316 \\
\hline \hline
\end{tabular}

<Table 7> Results of analysis of variance

\begin{tabular}{l|l|r|r|r|c}
\hline \hline Drafting Type1 & Drafting Type2 & Mean1 & Mean2 & \multicolumn{1}{c}{$(1-2)$} & t-test \\
\hline $\mathrm{c} 1$ & $\mathrm{c} 2$ & 2.265 & 3.377 & -1.112 & $* *$ \\
\hline $\mathrm{c} 1$ & $\mathrm{c} 3$ & 2.265 & 3.315 & -1.051 & $* *$ \\
\hline $\mathrm{c} 2$ & $\mathrm{c} 3$ & 3.377 & 3.315 & 0.062 & \\
\hline \hline$* *: \mathrm{p}<.01 \quad *: \mathrm{p}<.05$ &
\end{tabular}

c1: Sleeve Pattern of the Bunka drafting system, c2: Individual Sleeve Pattern, c3: Main Sleeve Pattern 
Cho Kyunghee / The Sleeve-Cap Part Drafting Method of the General-Purpose Sleeve Pattern and the Verification of Compatibility

(5) The Drafting Type of the Sleeve and the Results of the Analysis of Variances of (4)

$<$ Table 8> shows the drafting type of the sleeve and the results of the analysis of variances of (4). In the results of the analysis of variances, the evaluation between the drafting type of the sleeve and the level is significant so that the sleeve drafting method of the study is meaningful.

\section{How To Statistically Calculate the Coverage Rate from Data}

In <Table 9>, comparison among the compatible bodice, the sleeve and the main sleeve, and the pattern dimension of the sleeve is provided. The result shows that the allowance is added to the bodice width, sleeve width, and $\mathrm{AH}$ length in case of the main pattern.

Furthermore, the probability density (coverage rate) of the allowance of the sleeve width of the main sleeve pattern was considered. Generally, the measurement values of the ones existing in the nature have the certain form of distribution. It is called the normal distribution in statistics. In the measurement of a human body, height is generally known to nearly form the normal distribution. ${ }^{32)}$ However, as the histogram results of the allowance of the main sleeve width are shown in <Figure 4$\rangle$, the frequency shows the

$<$ Table 8> Results of analysis of variance

\begin{tabular}{l|r|r|r|c|c|r}
\hline \hline \multicolumn{1}{c|}{ factor } & \multicolumn{1}{c|}{ SS } & \multicolumn{1}{c|}{ df } & \multicolumn{1}{c|}{$\mathrm{V}$} & $\mathrm{F}$ & $\mathrm{P}$ & contribution ratio \\
\hline factor A & 158.538 & 2 & 79.269 & $96.319 * *$ & 0.000 & 23.960 \\
\hline $\mathrm{e}$ & 496.262 & 603 & 0.823 & & & 76.040 \\
\hline 합계 & 654.8 & 605 & & & & \\
\hline \hline$* *: \mathrm{p}<.01$ & $*: \mathrm{p}<05$
\end{tabular}

$<$ Table 9> Results of measurement items

\begin{tabular}{|c|c|c|c|c|}
\hline & Measurement items & Mean & S.D. & C.V. \\
\hline \multirow{5}{*}{ (1) } & $\mathrm{AH}$ & 41.10 & 2.43 & 0.06 \\
\hline & sleeve width & 32.38 & 2.68 & 0.08 \\
\hline & sleeve width ease & 4.52 & 0.90 & 0.20 \\
\hline & bodice width & 48.73 & 4.70 & 0.10 \\
\hline & bodice width ease & 5.34 & 1.61 & 0.30 \\
\hline \multirow{5}{*}{ (2) } & $\mathrm{AH}$ & 42.87 & 2.74 & 0.06 \\
\hline & sleeve width & 34.06 & 2.80 & 0.08 \\
\hline & sleeve width ease & 6.20 & 0.48 & 0.08 \\
\hline & bodice width & 50.41 & 4.77 & 0.09 \\
\hline & bodice width ease & 7.02 & 1.79 & 0.26 \\
\hline (2) & (2)-(1) $\mathrm{AH}$ & 1.77 & 0.48 & 0.27 \\
\hline- & ((2)-(1)) sleeve width ease & 1.68 & 1.10 & 0.65 \\
\hline (1) & (2)-(1) bodice width ease & 1.68 & 0.53 & 0.32 \\
\hline
\end{tabular}

(1): Compatible Sleeve Pattern, (2): Main Sleeve Pattern 
static non-symmetric shape with the left steep slope and the right gentle slope. It has been shown in the precedent study ${ }^{33)}$ that the measurement values of the bust circumference and waist circumference relating to the obesity index show the static non-symmetric shape. The sleeve width is also the item showing significantly high correlation with the items relating to the obesity index. ${ }^{34)}$ In spite of 7 samples, the data showed the same tendency.

The coverage rate was found statistically from the above review results to review how many people can wear them by using the population of the subjects of the study and the allowance of the sleeve width of the main sleeve pattern shown in $\langle$ Table 9>.

In the study, the probability density was found statistically with the normal distribution table ${ }^{37)}$ with the reference to the order to finding the dimension from the coverage rate of the precedent studies ${ }^{35 / 36)}$ stated in Miyoshi's "The Factors of Pattern-Making". In the population, the results

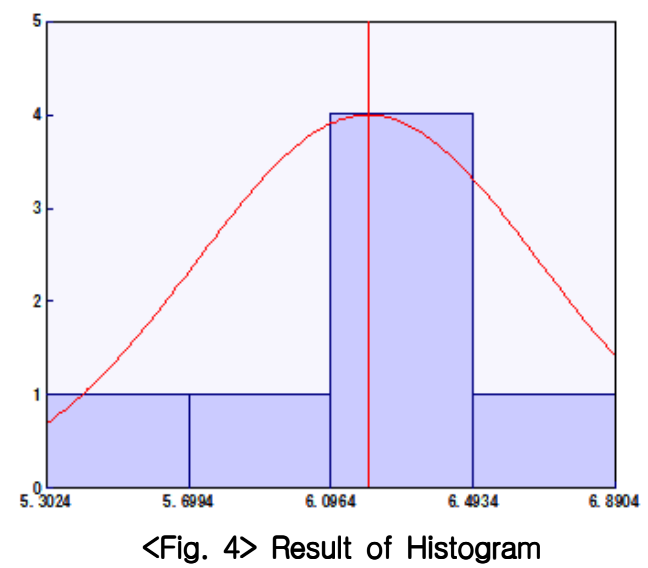

show that $50 \%$ out of total is included up to $4.52 \mathrm{~cm}$, the allowance of the compatible sleeve. It is known from the calculation that $97 \%$ of the people is included up to $6.2 \mathrm{~cm}$, the allowance of the sleeve width of the main sleeve. It was accepted for the data only that it is almost valid as the range of the general-purpose sleeve in general.

\section{Consideration of the Simplification of the Equation to Calculate the Dimension}

In order to make it easy for ordinary people to use the regression equation utilized for drafting, it is necessary to avoid the complexity of the equation to calculate the dimension and simplify the equation to calculate the dimension. In the recent material, the one place of decimals is represented in the drafting method ${ }^{14)}$ of the basic Bunka sleeve.

$<$ Figure 10> showed the simplification results on the sleeve-cap height, front and back sleeve width, front and back sleeve-cap width, and height of the front and back sleeve-cap width items that are the major components of the sleeve pattern out of the results of the regression equation used for the sleeve pattern for individuals. The simplification close to the experiment value was thought to be valid so that the coefficient of the regression equation was simplified by rounding off to the nearest integer at least up to the two places of decimals. Furthermore, the results of the final regression equation of the individual sleeve and the main sleeve were presented.

The coefficient multiplied by the explanatory variable was modified into the fraction, and the equation was modified for the easy comparison with the general basic pattern drafting method and for the easy consideration as the grade quantity. Miyoshi points out that the regression coefficient is the standard of the grading of the part for mass production. ${ }^{38)}$ As for the simpli fication of the equation to calculate dimensions, 
Cho Kyunghee / The Sleeve-Cap Part Drafting Method of the General-Purpose Sleeve Pattern and the Verification of Compatibility

$<$ Table 10> Simplification of a regression basic pattern and Result of Main Sleeve Pattern

\begin{tabular}{l|l|c|c|c}
\hline \hline \multicolumn{1}{c|}{$\mathrm{Y}$ : Taget variable } & \multicolumn{1}{c|}{$\mathrm{X}$ : Explanatory variable } & Individual sleeve pattern & Added value & Main sleeve pattern \\
\hline height of sleeve cap & sp a point & $\mathrm{Y}=\mathrm{X} / 1.29+2.71$ & & $\mathrm{Y}=\mathrm{X} / 1.29+2.71$ \\
\hline sleeve width & upper arm girth & $\mathrm{Y}=\mathrm{X} / 1.09+6.83$ & 1.68 & $\mathrm{Y}=\mathrm{X} / 1.09+8.51$ \\
\hline sleeve width(back) & upper arm girth & $\mathrm{Y}=\mathrm{X} / 1.43-1.93$ & 0.81 & $\mathrm{Y}=\mathrm{X} / 1.43-1.12$ \\
\hline sleeve cap width & upper arm girth & $\mathrm{Y}=\mathrm{X} / 2.36+7.68$ & 0.27 & $\mathrm{Y}=\mathrm{X} / 2.36+7.95$ \\
\hline sleeve cap width(back) & horizontal arm surface length & $\mathrm{Y}=\mathrm{X} / 1.13+2.01$ & 0.15 & $\mathrm{Y}=\mathrm{X} / 1.13+2.16$ \\
\hline height of sleeve cap width(front) & height of front armpit point & $\mathrm{Y}=\mathrm{X} / 0.82-1.82$ & & $\mathrm{Y}=\mathrm{X} / 0.82-1.82$ \\
\hline height of sleeve cap width(back) & height of back armpit point & $\mathrm{Y}=\mathrm{X} / 0.91-0.69$ & & $\mathrm{Y}=\mathrm{X} / 0.91-0.69$ \\
\hline
\end{tabular}

$\mathrm{sp}$ a point : silhouette line length between the shoulder point(sp) and the point of upper arm

horizontal arm surface length : horizontal arm surface length of back armpit point

the same method as Miyoshi's method was selected. When the explanatory variable was average, the value of each target variable was to maintain the average as a rule so that the difference generated from the shortening of the denominator was adjusted according to the increase and decrease of the integer term. ${ }^{39)}$

As shown in $\langle$ Table 10$\rangle$, they were usable as the sleeve width and sleeve-cap width of the general-purpose basic sleeve pattern by increasing the quantity added to the back breadth, side breadth, and chest breadth to the integer term of the regression equation of the sleeve width and the sleeve-cap width.

\section{Conclusion and Suggestions}

In the study, the sensory test was done to verify the compatibility of the basic sleeve pattern for individuals, main sleeve pattern, and basic sleeve pattern of the Bunka drafting system to review the validity of the sleeve drafting system found with the regression equation. The conclusion is as follows.

1. The $0.66 \mathrm{~cm}$ shortage of the compatible basic bodice pattern was proportionately distributed to the general-purpose sleeve. Hence, it was possible to use it as the general- purpose basic sleeve pattern.

Furthermore, as the result of measuring the length of the oblique lines of the front and back sleeve-caps, it was found that as for the length of the oblique lines of the front and back sleeve-caps of the individual sleeve made by using the regression equation, the ease portion is added to the front, back, and $\mathrm{AH}$ dimensions of the compatible bodice pattern and that it can be used as sleeve pattern.

2. The decision on the sensory test done by the panel of 30 persons was made by observing the wearing state of the experiment costume from the front, back, and side photos of the models wearing the experiment costumes made as the basic sleeve pattern for individuals, main sleeve pattern, and the basic sleeve pattern of the Bunka drafting system.

In general, the basic sleeve pattern for individuals and main sleeve pattern made by using the regression equation received the evaluation of the three points in average and the evaluation significantly higher than the basic sleeve pattern of the Bunka drafting system with the 2 points in average. Moreover, the analysis of variances based on the evaluation items of the sleeve drafting type and the compatibility state of all arms resulted in the clearly significant difference so that the sleeve drafting 
method of the study was significant. From these results, the basic sleeve pattern for individuals and the main sleeve pattern were more compatible with the form characteristics of the human arms so that the compatibility of the new sleeve drafting system and the validity of the drafting theory were verified.

3. The 7 samples of the study were classified into the three body types based on BMl to consider the relation with the sleeve system type. The obese body type showed the tendency of the fit being a bit worse than the thin body type. The difference ratio was different for each drafting type of the sleeve. Namely, the individual sleeve was a bit high in the average body type. the devised general-purpose sleeve was high in the obese body type.

4. The probability density (coverage rate) of the room of the sleeve width was found. As for the coverage rate of the room of the sleeve width, $50 \%$ out of total is included in the population up to $4.52 \mathrm{~cm}$, the allowance of the compatible sleeve. It was known from the calculation that $97 \%$ of the people is included up to $6.2 \mathrm{~cm}$, the allowance of general-purpose sleeve. It was accepted for the data only that it is valid as the range of the general-purpose sleeve in general.

5. In order to make it easy for ordinary people to use the regression equation utilized for drafting, it was thought to be necessary to simplify the equation to calculate the dimension so that the equation to calculate the dimension in the drafting of the sleeve-cap part was simplified. They were usable as the general-purpose basic sleeve pattern by increasing the quantity added to the back breadth, side breadth, and chest breadth to the integer term of the regression equation of the sleeve width and the sleeve-cap width.
The study has the limitation of deriving the drafting method of the sleeve-cap of the general-purpose sleeve by finding out the regression equation for the limited subjects of 7 samples so that care is required to generalize the conclusion. However, the subjects with the clear body form difference effectively produced the significant results so that the result was significant. The basic data usable as the general purpose sleeve was prepared by increasing the number of subjects.

The precision of the regression equation by adding the number of samples on the basis of the methodology proposed in the study will be enhanced. Furthermore, the further study on the automatic design of the sleeve pattern for individuals will be done.

\section{Reference}

1) Cho Kyunghee, Miyoshi Machiko(2005), "Relationship between the Sleeve Patterns for Female Adults and Characteristics of arms and Upper Trunks", Journal of the Japan Research Association for textile end-uses, 46(10), pp.647-662.

2) Machiko Miyoshi supervision(2001), Modeling science of clothes The theory volume 1, Tokyo: Bunka school textbook Press, p.151.

3) Miyoshi Machiko, Nakamoto Setsuko(1990), "Consideration of a research work-tansunsiki drawing way about the upper part of body prototype drawing way for adult girls", The Japan Society of Home Economics, 4111 2), p.1213.

4) Cho Kyunghee, Miyoshi Machiko(2008), "A Study on the Pattern Making Theory for Design of Sleeve Cap Part of Sleeve Pattern Appropriate for the Characteristics of Arm 
Cho Kyunghee / The Sleeve-Cap Part Drafting Method of the General-Purpose Sleeve Pattern and the Verification of Compatibility

Form", Journal of the Korean Society of Clothing and Textiles, 32(4), pp.641-650.

5) Bunka Fashion College(editor)(1984), Bunka Fashion course. woman's dress 1, Tokyo: Bunka school textbook Press, pp.80-81.

6) Doi SACHIYO, et al.(1986), Body Type and Clothes, Tokyo: Dobunsyoin, pp.101-103.

7) Yanagisawa Sumiko, Harada Huzie(1966), Fundamentals and Applications of Dress Pattern, Tokyo: Shibatashoten, pp.51-52.

8) Isamu Karaki(1979), New flat pattern system for apparel designing, Tokyo: Vantan Design Institute All rights reserved, pp.62-69.

9) Renko Kondo(1988), modeling Theory of women's clothing and Pattern of Renko Kondo, Tokyo: Genryusha, pp.178-201.

10) Norimitsu Shibayama(2004), continuance. Questions and answers built with clothes, Tokyo: THE APPAREL INDUSTRIAL TIMES, pp.8-11.

11) Yoshiko Sugino(1968), New DOREME system dressmaking(phase), Tokyo: Kobunsha Publishing, pp.36-37.

12) Sugiyama Fujiko, et al.(1966), Composition of clothes The first volume, Tokyo: HirokawaShoten, p.52.

13) Chiyo Tanaka(1966), Dressmaking, Osaka: Doshisha, pp.74-78.

14) Miyoshi Machiko supervision, op. cit., pp.129-133.

15) Masanori Maki(2002), ELEGANZA NAPOL/, Tokyo: Maki and MODERISUTOOFISU, pp. 13-15.

16) Amano Takako, Ito Keiko, Sekiguchi Chiho(2000), "Sleeve Fitting II", Bulletin of Sugino Women's College Sugino Women's Junior College, 37, pp.51-60.

17) Istituto Carlo Secoli(2003), Modellistica Industriale Donna, Milano: Institution Carlo Secoli, pp.1-60.
18) Jai-Un To(1989), Pattern Design and Fabrication Method, SHINKWANGPUB, pp. 64-69.

19) Myung Eun Choi, Won Ja Rim(1989), "A Study on Armscye Section and Development of Sleeve Pattern Drafting Method", Journal of the Korean Home Economics Association, 27(4), pp.1-9.

20) Won Ja Rim(2000), Clothing Construction (2nd ed.), Paju: KYOMUNSA, pp.12-14.

21) Hyoung-Sook Lee, Yun-Ja Nam(2007), Patternmaking for Women's Wear(2nd ed.), Kyohak Publishing, pp.102-108.

22) Miyoshi Machiko supervision, op. cit., pp. 170-172.

23) Cho Kyunghee, Miyoshi Machiko(2008), op. cit., p.645.

24) Cho Kyunghee(1997), "A Study on Bodice and Sleeve Basic Pattern adapted to upper limb movement", Bunka Women's University master's dissertation, pp.33-42.

25) Junnosuke Ono supervision(1990), The quick answer, Tokyo: AMIKOFASSHONZU, p.11.

26) Cho Kyunghee, Miyoshi Machiko(2005), op. cit., pp.654-655.

27) Miyoshi Machiko supervision, op. cit., pp. 235-236.

28) Cho Kyunghee, Miyoshi Machiko(2003), "A Study on Characteristics of Forms of Women's Arms and Upper Trunks for the Pattern-Making System of Sleeves", Journal of the Japan Research Association for textile end-uses, 44( 1), pp.48-50.

29) Miyoshi Machiko supervision, op. cit., pp. 237-238.

30) Cho Kyunghee, Miyoshi Machiko(2008), op. cit., pp.644-646.

31) Cho Kyunghee, Miyoshi Machiko(2005), op. cit., pp.650-651.

32) The Japanese Standards Association(editor) 
(1984), Physique Research Report of the Japanese(1978 1981), p.265.

33) Miyoshi Machiko, Hirokawa Taeko, Saito Kayo, et al.(1997), "Consideration of a change by the distribution and the age of the Tokyo area adult female human body measured value", Bulletin of Bunka Women's University, 28, pp.69-83.

34) Cho Kyunghee, Miyoshi Machiko(2005), op. cit., pp.658-660.

35) Miyoshi Machiko(1983), "The Factors of Pattern-Making/V", Clothing habit workshop 26(3), pp.16-23.

36) Miyoshi Machiko(1984), "The Factors of Pattern-MakingVII", Clothing habit workshop 27(2), pp.36-43.
37) Journal of the Japan Research Association for textile end-uses(1974), Data processing method for Journal of the Japan Research Association for textile end-uses example with a focus on consumption Science, p.153.

38) Miyoshi Machiko(1984), "The Factors of Pattern-MakingVII", Clothing habit workshop 27(4), pp.41-48.

39) Miyoshi Machiko, Nagatomi Akiko(2004), "An Improved Method of Estimating Grading Scales for Proportional Basic Patterns for Adult Women's Upper Garments(part1)", Journal of the Japan Research Association for textile end-uses, 45(4), pp.288-301.

Received Jul. 2, 2012

Revised (Jul. 9, 2012)

Accepted Jul. 13, 2012 